\title{
Relationship between Epicardial and Coronary Adipose Tissue and the Expression of Adiponectin, Leptin, and Interleukin 6 in Patients with Coronary Artery Disease
}

\author{
Olga V. Gruzdeva, Yulia A. Dyleva *(D), Ekaterina V. Belik (D), Maxim Y. Sinitsky (D), Aleksandr N. Stasev, \\ Aleksandr N. Kokov (D), Natalia K. Brel, Evgenia O. Krivkina, Evgenia E. Bychkova, Roman S. Tarasov $\mathbb{D}$ \\ and Olga L. Barbarash
}

check for updates

Citation: Gruzdeva, O.V.; Dyleva, Y.A.; Belik, E.V.; Sinitsky, M.Y.; Stasev, A.N.; Kokov, A.N.; Brel, N.K.; Krivkina, E.O.; Bychkova, E.E.; Tarasov, R.S.; et al. Relationship between Epicardial and Coronary Adipose Tissue and the Expression of Adiponectin, Leptin, and Interleukin 6 in Patients with Coronary Artery Disease. J. Pers. Med. 2022, 12, 129. https://doi.org/10.3390/ jpm12020129

Academic Editor: Theodoros Papaioannou

Received: 7 December 2021

Accepted: 17 January 2022

Published: 19 January 2022

Publisher's Note: MDPI stays neutral with regard to jurisdictional claims in published maps and institutional affiliations.

Copyright: (C) 2022 by the authors. Licensee MDPI, Basel, Switzerland. This article is an open access article distributed under the terms and conditions of the Creative Commons Attribution (CC BY) license (https:// creativecommons.org/licenses/by/ $4.0 /)$.
Federal State Budgetary Scientific Institution "Research Institute for Complex Issues of Cardiovascular Diseases", 650002 Kemerovo, Russia; o_gruzdeva@mail.ru (O.V.G.); sionina.ev@mail.ru (E.V.B.); sinitsky.maxim@gmail.com (M.Y.S.); stasan@kemcardio.ru (A.N.S.); kokoan@kemcardio.ru (A.N.K.); brel.n.k@mail.ru (N.K.B.); kriveo@kemcardio.ru (E.O.K.); eugenia.tarasowa@yandex.ru (E.E.B.); tarars@kemcardio.ru (R.S.T.); barb61@yandex.ru (O.L.B.)

* Correspondence: dyleva87@yandex.ru

\begin{abstract}
Adipose tissue (AT) is an endocrine and paracrine organ that synthesizes biologically active adipocytokines, which affect inflammation, fibrosis, and atherogenesis. Epicardial and perivascular fat depots are of great interest to researchers, owing to their potential effects on the myocardium and blood vessels. The aim of the study was to assess the expression and secretion of adipocytokine genes in the AT of patients with coronary artery disease (CAD) and patients with aortic or mitral valve replacement. This study included 84 patients with CAD and 50 patients with aortic or mitral valve replacement. Adipocytes were isolated from subcutaneous, epicardial (EAT), and perivascular AT (PVAT), and were cultured for $24 \mathrm{~h}$. EAT exhibited the lowest level of adiponectin gene expression and secretion, regardless of nosology, and high expression levels of the leptin gene and interleukin- 6 (IL-6). However, EAT adipocytes in patients with CAD were characterized by more pronounced changes in comparison with the group with heart defects. High leptin and IL-6 levels resulted in increased pro-inflammatory activity, as observed in both EAT and PVAT adipocytes, especially in individuals with CAD. Therefore, our results revealed the pathogenetic significance of alterations in the adipokine and cytokine status of adipocytes of EAT and PVAT in patients with CAD.
\end{abstract}

Keywords: adiponectin; leptin; interleukin-6; epicardial adipose tissue; perivascular adipose tissue

\section{Introduction}

Atherosclerosis-related cardiovascular disease (CVD) remains one of the main causes of death in industrialized countries, despite significant achievements in modern medicine [1]. Moreover, the increasing incidence of obesity is likely to aggravate this problem. Adipose tissue (AT) is universally regarded as an endocrine and paracrine organ that synthesizes biologically active molecules. Adipocytokines are involved in various processes, including inflammation, fibrosis, and atherogenesis [2-4]. It has been shown that local fat depots, such as epicardial (EAT) and perivascular AT (PVAT), are associated with increased cardiovascular events, independent of traditional risk factors [5]. In addition, reports have shown differences in the matrix RNA (mRNA) expression of adipokines in epicardial and subcutaneous AT (SAT) [6]. As different fat depots are characterized by their unique adipocytokinome and secretome, studies on the role of AT adipocytokines at different locations and CVD are relevant.

EAT is of particular interest owing to its close location to the coronary arteries and its possible paracrine action on them [7]. When inflammatory processes are activated, the epicardium becomes a site of impaired adipogenesis, which leads to the secretion of 
pro-inflammatory adipokines and fibrosis of the atrial and ventricular myocardium. PVAT is also of interest, since its heterogeneity determines the functions of ATs-protective or atherogenic. EAT and PVAT have been shown to be associated with coronary artery disease (CAD) [8]. However, the mechanisms by which adipocytokines affect the pathogenesis of CVD are still not fully understood. Thus, it is necessary to study the expression of adipokine genes in AT in various sites to develop potential therapeutic interventions against pathological activation of AT in CVD.

\section{Material and Methods}

\subsection{Study Inclusion Criteria}

Inclusion criteria consisted of the following: $\mathrm{CAD}$, presence of indications for coronary artery bypass grafting (CABG) (based on coronarography data), patient age up to 75 years, and patient consent for participating in the study. Exclusion criteria were as follows: patient age greater than 75 years; presence of type 1 and type 2 diabetes mellitus (DM) as evident in his/her medical history and/or revealed during the hospitalization examination, acute of pervious myocardial infarction (MI), presence of clinically significant comorbidities (anemia, kidney and liver failure, oncological and infectious-inflammatory diseases) in the period of exacerbation, autoimmune diseases, and refusal to participate in the study.

\subsection{Study Population}

The study included 125 patients with CAD and indications for direct myocardial revascularization by CABG. The study group consisted of 31 women (25\%) and 94 men $(75 \%)$, of an average age of $65.32(57.35 ; 69.16)$ years (Table 1$)$. In the patient history, hypertension, smoking, angina pectoris, and burdened heredity for cardiovascular pathology were recorded more often. In total, 86 patients had a previous history of MI, and 11 people had a history of stroke. The comparison group included 120 patients with heart defects (aortic or mitral valve replacement), consisting of individuals of an average age of 61.22 $(55.49 ; 66.65)$ years (Table 1$)$ without coronary atherosclerosis (as per coronary angiography). Individuals in group with heart defects were characterized by a low percentage of patients with cardiovascular risk factors.

Table 1. Clinical and anamnestic characteristics of patients with coronary artery disease and heart defects.

\begin{tabular}{cccc}
\hline Parameter & CAD $(\boldsymbol{n = 1 2 5 )}$ & Heart Defects $(\boldsymbol{n = 1 2 0})$ & $p$ \\
\hline Men, $n(\%)$ & $97(77.6)$ & $60(50)$ & 0.011 \\
Body mass index, $\mathrm{kg} / \mathrm{m}^{2}$ & $28.89(26.64 ; 32.12)$ & $26.78(23.21 ; 29.01)$ & 0.069 \\
Arterial hypertension, $n(\%)$ & $118(94.4)$ & $32(26.7)$ & 0.001 \\
Hypercholesterolemia, $n(\%)$ & $31(24.8)$ & $16(13.3)$ & 0.025 \\
Smoking, $n(\%)$ & $90(72)$ & $10(8.3)$ & 0.0001 \\
Family history of CAD, $n(\%)$ & Anamnesis & $42(35)$ & 0.014 \\
History of myocardial infarction, & $76(60.8)$ & 0 & - \\
$n(\%)$ & $86(68.8)$ & 0 & - \\
History of stroke, $n(\%)$ & $11(8.8)$ & 0 & - \\
Atherosclerosis of other pools, $n$ & $21(16.8)$ & $120(100)$ & 0.0001 \\
$(\%)$ & $8(6.4)$ & 0 & - \\
No angina, $n(\%)$ & 0 & 0 & - \\
Functional class I angina, $n(\%)$ & $51(40.8)$ & 0 & 0.030 \\
Functional class II angina, $n(\%)$ & $66(52.8)$ & $26(21.7)$ & \\
Functional class III angina, $n(\%)$ & $16(12.8)$ & & \\
Chronic heart failure NYHA I & & & \\
functional class, $n(\%)$ & & & \\
\hline
\end{tabular}


Table 1. Cont.

\begin{tabular}{|c|c|c|c|}
\hline Parameter & CAD $(n=125)$ & Heart Defects $(n=120)$ & $p$ \\
\hline $\begin{array}{l}\text { Chronic heart failure NYHA II } \\
\text { functional class, } n(\%)\end{array}$ & $11(8.8)$ & $54(45)$ & 0.0002 \\
\hline $\begin{array}{l}\text { Chronic heart failure NYHA III } \\
\text { functional class, } n(\%)\end{array}$ & $7(5.6)$ & $40(33.3)$ & 0.003 \\
\hline $\begin{array}{l}\text { Chronic heart failure NYHA IV } \\
\text { functional class, } n(\%)\end{array}$ & 0 & 0 & - \\
\hline $\begin{array}{l}\text { Atherosclerosis of the 1st } \\
\text { coronary artery, } n(\%)\end{array}$ & $10(8)$ & 0 & - \\
\hline $\begin{array}{l}\text { Atherosclerosis of the } 2 \text { nd } \\
\text { coronary artery, } n(\%)\end{array}$ & $6(4.8)$ & 0 & - \\
\hline $\begin{array}{l}\text { Atherosclerosis of three or more } \\
\text { coronary artery, } n(\%)\end{array}$ & $109(87.2)$ & 0 & - \\
\hline Ejection fraction, $\%$ & $51.0(44.13 ; 56.377)$ & $53.2(43.41 ; 58.03)$ & 0.125 \\
\hline \multicolumn{4}{|c|}{ Treatment strategy/group of drugs (hospital period) } \\
\hline Aspirin, $n(\%)$ & $122(97.6)$ & 0 & - \\
\hline Clopidogrel, $n(\%)$ & $21(16.8)$ & 0 & - \\
\hline Warfarin, $n(\%)$ & 0 & $103(85.8)$ & - \\
\hline$\beta$-blockers, $n(\%)$ & $122(97.6)$ & $111(92.5)$ & 0.312 \\
\hline $\begin{array}{c}\text { Angiotensin-converting enzyme, } \\
n(\%)\end{array}$ & $96(76.8)$ & $95(79.2)$ & 0.247 \\
\hline Statins, $n(\%)$ & $125(100)$ & $98(81.7)$ & 0.033 \\
\hline $\begin{array}{l}\text { Calcium channel } \\
\text { Blocker, } n(\%)\end{array}$ & $96(76.8)$ & $90(75)$ & 0.151 \\
\hline Nitrates, $n(\%)$ & $11(8.8)$ & $10(8.3)$ & 0.417 \\
\hline Diuretics, $n(\%)$ & $105(84)$ & $110(91.7)$ & 0.062 \\
\hline
\end{tabular}

Notes: Hereinafter: CAD, groups of patients with coronary artery disease and indications for direct myocardial revascularization by coronary artery bypass grafting, $p$, significance level.

All patients were administered standard antianginal and antiplatelet therapies throughout the observation period and in-hospital treatment period (Table 1).

\subsection{Measurement of the Area of SAT, EAT, and PVAT}

For all patients, the area was measured as abdominal AT, namely, its visceral and subcutaneous components, using multi-spiral computed tomography (MSCT) on a Siemens Somatom 64 computed tomography scanner (Siemens Healthcare, Erlangen, Germany). Scanning was performed at the level of vertebral bodies L4-L5 in the craniocaudal direction. At the level of the intervertebral disc L4-L5, the area of abdominal adipose tissue (AAT) was measured in a semi-automatic mode. Further, the area of visceral adipose tissue (VAT) was determined on the obtained image by highlighting the contour of the peritoneum. The area of SAT was calculated mathematically by subtracting the area of VAT from the area of AAT (Figure 1a).

The determination of EAT thickness was performed by magnetic resonance imaging (MRI) on an Exelart Atlas 1.5-T MR imager (Toshiba, Tokyo, Japan). Thickness measurements of EAT was performed on images oriented along the short axis of the heart. EAT thickness was measured at three points along the anterior wall of the right ventricle, after which the average value was calculated. In addition, the same method was used to measure EAT thickness at the back wall of the left ventricle, followed by the calculation of the mean value (Figure 1b). 

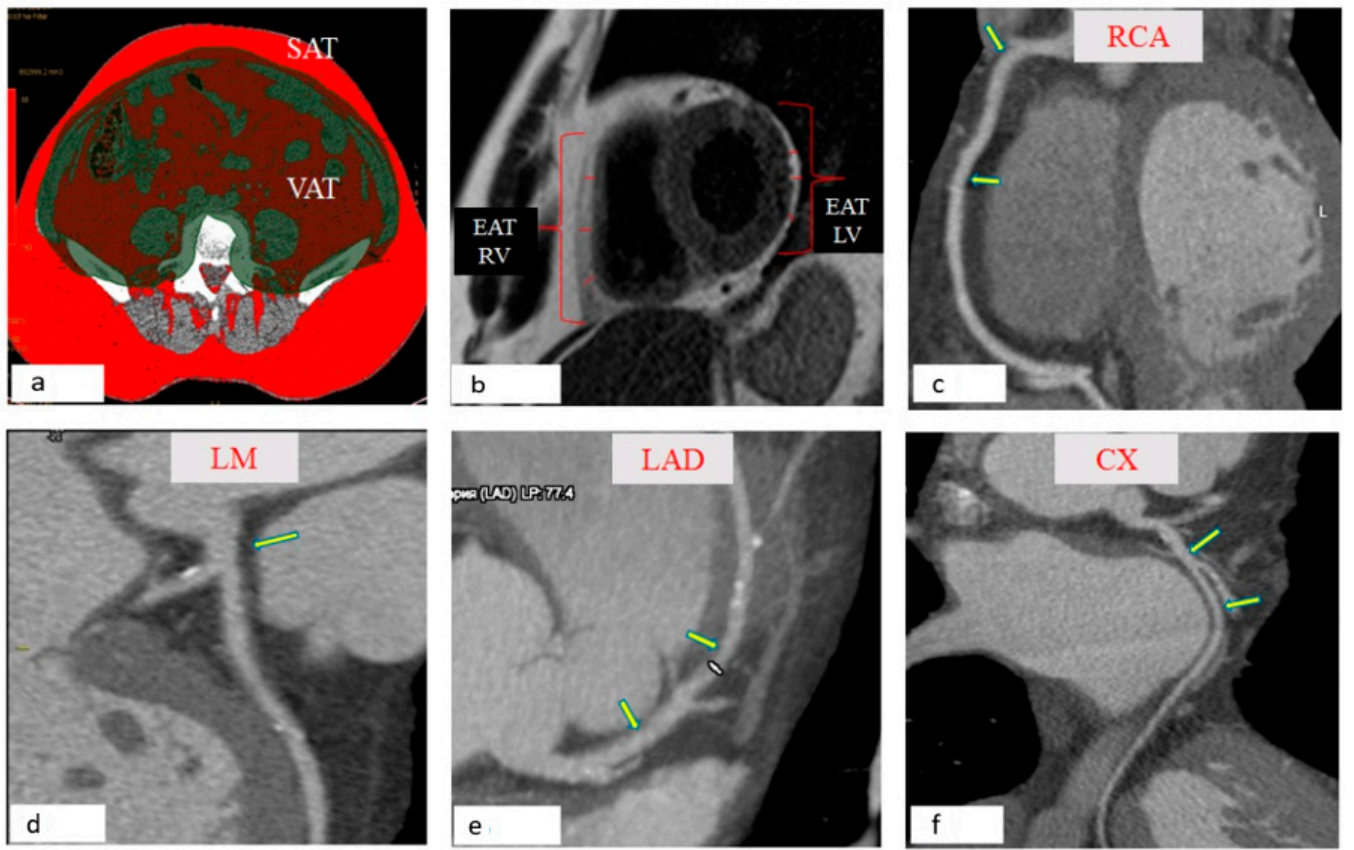

Figure 1. Morphometric assessment of local fat depots. (a) Slices centered at the L4-L5 disc spaces were selected. Visceral fat was defined as the fat enclosed by the visceral cavity. Subcutaneous fat was defined as fat outside the visceral cavity, not including that located within the muscular fascia. The total visceral and subcutaneous fat area $\left(\mathrm{cm}^{2}\right)$ were automatically calculated using a workstation (Leonardo, Siemens, Germany). (b) EAT was defined as the adipose tissue located between the visceral layer of the pericardium and outer surface of the myocardium. EAT was measured on the horizontal long-axis plane in end-diastolic phase. The EAT thickness of the right and left ventricular free wall was recorded by averaging the measurements of 3 different levels. (c) The thickness of the PVAT right coronary artery (RCA) was measured at the level of the proximal third of the RCA, for which the orifice of the acute margin artery is the distal end, in the projection of the middle third of the RCA, bounded by the arteries of the acute margin and the posterior interventricular branch of the right coronary artery. (d) The thickness of the PVAT of the left coronary artery (LCA) was measured at the level of the left main (LM) coronary artery (Figure 1d). (e) The PVAT was assessed at the level of the proximal and middle third of the anterior descending artery (LAD). The proximal third of LAD is a site from the orifice to the origin of the first diagonal artery, while the middle third of the LAD is limited by the orifices of the first and second diagonal arteries. (f) The thickness of the PVAT was estimated at the level of the proximal third of the circumflex coronary arteries (CX), which is limited by the ostium of the $\mathrm{CX}$ and the branch of the obtuse edge and at the level of the middle third of the CX-a segment from the branch of the obtuse edge to the orifice of the posterior interventricular artery.

Determination of the thickness of the PVAT at different anatomical locations was performed using the MSCT method with the following parameters: $1 \mathrm{~mm}$ axial slice thickness, an image matrix of $512 \times 512$, tube voltage of $120 \mathrm{kV}$, and a tube current of $100 \mathrm{~mA}$. The MSCT images were acquired using bolus contrast, followed by a quantitative evaluation. The thickness of the PVAT of the right coronary artery (RCA) was measured at the level of the proximal third and in the projection of the middle third of the RCA (Figure 1c). The thickness of the PVAT of the left coronary artery (LCA) was measured at the level of the left main (LM) coronary artery (Figure 1d). The thickness of the PVAT of the anterior descending coronary artery (LAD) was measured at the level of the proximal and middle third of the LAD (Figure 1e). The thickness of the PVAT of the circumflex coronary arteries (CX) was measured at the level of the proximal third of the CX (Figure 1f). The obtained DICOM images were processed on a "Leonardo" multimodal workstation. 


\subsection{Cell Collection}

\subsubsection{Obtaining Biopsies of AT from Various Sites}

Biopsies of 3-5 g of SAT, EAT, and PVAT samples were obtained during coronary bypass surgery and heart defects (aortic or mitral valve replacement). SAT samples were obtained from the subcutaneous tissue of the lower angle of the mediastinal wound. EAT samples were obtained from the right heart (right atrium and right ventricle), and PVAT samples were obtained from the area of the right coronary artery. The AT samples were placed in Hanks' Balanced Salt Solution (Merck KGaA, St. Louis, MO, USA) containing penicillin $(100 \mathrm{U} / \mathrm{L})$, streptomycin $(100 \mathrm{mg} / \mathrm{mL})$, and gentamicin $(50 \mu \mathrm{g} / \mathrm{mL})$.

Adipose depots were harvested and fixed overnight in 10\% neutral buffered formalin. Sections obtained from paraffin-embedded tissues were stained with hematoxylin and eosin (H\&E) using standard protocols (Figure 2).
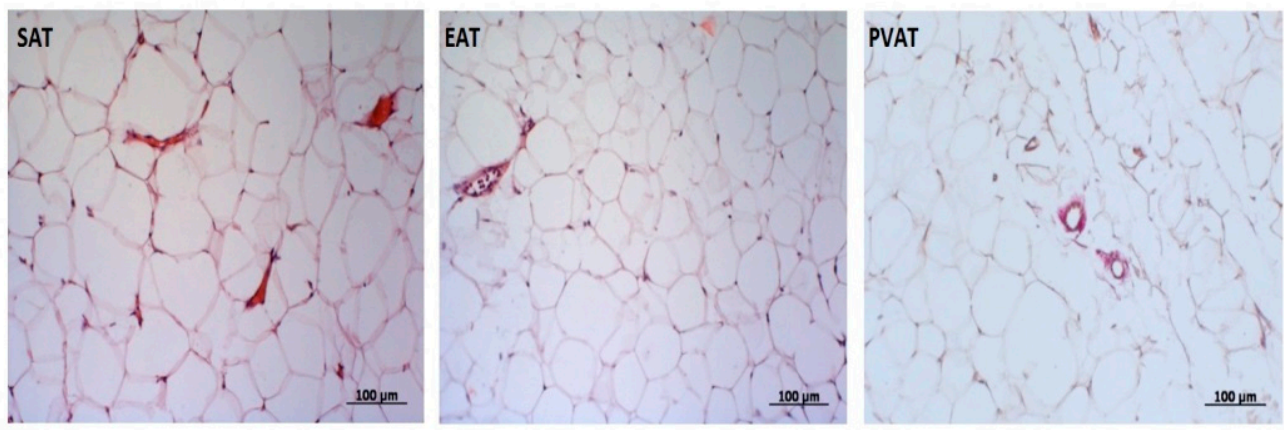

Figure 2. Representative microphotographs of hematoxylin and eosin (upper panels) stained samples of subcutaneous (SAT), epicardial (EAT) and perivascular (PVAT) from patients with coronary artery disease. Scale bar $=100 \mu \mathrm{m}$.

\subsubsection{Adipocyte Extraction and Culture}

Adipocytes were isolated from ATs under sterile conditions in a laminar flow hood (BOV-001-AMS MZMO, Millerovo, Russia) using a previously described method [9]. Adipose tissue samples (3-5 g) were crushed to 1-3 $\mathrm{mm}^{3}$ fragments and incubated in a collagenase type I solution $(0.5 \mathrm{mg} / \mathrm{mL})$ (Thermo Fisher Scientific, Waltham, MA, USA) containing $200 \mathrm{nM}$ adenosine (Merck KGaA, St. Louis, MO, USA) at $37{ }^{\circ} \mathrm{C}$ for $30 \mathrm{~min}$. Then, the adipocytes were poured through a Falcon ${ }^{\mathrm{TM}} 100 \mu \mathrm{m}$ sterile mesh (Thermo Fisher Scientific, Waltham, MA, USA) and washed with Gibco ${ }^{\circledR}$ M199 culture medium (Thermo Fisher Scientific), 1\% 4-(2-hydroxyethyl)-1-piperazineethanesulfonic acid buffer (Thermo Fisher Scientific), 1\% l-glutamine with penicillin and streptomycin (Thermo Fisher Scientific), 0.4\% amphotericin B (Thermo Fisher Scientific), glucose of $5 \mathrm{mmol} / \mathrm{L}, 10 \%$ fetal bovine serum (Thermo Fisher Scientific). The volume of the liquid containing the cells was adjusted to $5 \mathrm{~mL}$ using culture medium, and the cells were centrifuged for $2 \mathrm{~min}$ at $200 \times \mathrm{g}$. Isolated adipocytes (supernatant) were placed in a separate tube, and the volume was adjusted to $1 \mathrm{~mL}$ with culture medium. Adipocytes were counted in a Goryaev's chamber. Cell viability was evaluated according to the method described by Suga et al. [10]. Adipocytes $\left(20 \times 10^{5}\right)$ were seeded into a 24-well plate (Greiner Bio One International GmbH, Kremsmünster, Austria), and the volume in each well was adjusted to $1 \mathrm{~mL}$ with culture medium. The plates were incubated for $24 \mathrm{~h}$ at a temperature of $37 \pm 1{ }^{\circ} \mathrm{C}$ in an atmosphere of $5 \%$ carbon dioxide and $10 \%$ oxygen. Subsequently, the adipocytes were carefully extracted from the surface of the culture medium to determine the expression of adipokine and cytokine genes and the culture medium was also extracted from the bottom of the wells for the determination of adipokine and cytokine levels by enzyme-linked immunoassay (ELISA). 


\subsection{Laboratory Assays}

\subsubsection{RNA Extraction}

Total RNA purification from isolated adipocytes was performed using the commercial RNeasy ${ }^{\circledR}$ Plus Universal Mini Kit (Qiagen, Hilden, Germany), according to the manufacturer's protocol with slight modifications, as described previously [11]. Extracted RNA was stored at $-70{ }^{\circ} \mathrm{C}$ until use.

The quantity and quality of purified RNA were assessed using a NanoDrop 2000 Spectrophotometer (Thermo Fisher Scientific) by measuring the light absorbance at $280 \mathrm{~nm}$, $260 \mathrm{~nm}$, and $230 \mathrm{~nm}$ and calculating the 260/280 (A260/280) and 260/230 (A260/230) ratios. The integrity of the RNA was determined by electrophoresis in agarose gels, followed by visualization using the Gel Doc ${ }^{\mathrm{TM}} \mathrm{XR}+$ System (Bio-Rad, Hercules, CA, USA).

\subsection{2. cDNA Synthesis}

Single-stranded cDNA was synthesized using the High-Capacity cDNA Reverse Transcription Kit (Applied Biosystems, Foster City, CA, USA) on a VeritiTM 96-Well Thermal Cycler (Applied Biosystems, Waltham, MA, USA). Reverse transcription was performed using the program settings suggested by the kit's manufacturer. The quantity and quality of synthesized cDNA were assessed using a NanoDrop 2000 Spectrophotometer. Samples were stored at $-20{ }^{\circ} \mathrm{C}$.

\subsubsection{Real Time Quantitative Polymerase Chain Reaction (qRT-PCR)}

Expression of the adiponectin, leptin, leptin receptor and interleukin-6 (IL-6) genes was evaluated by quantitative real-time polymerase chain reaction (qPCR) using TaqManTM Gene Expression Assays (ADIPOQ Hs00605917_m1, LEP Hs00174877_m1, LEPR Hs00174497_m1, IL6 Hs00174131_m1, Applied Biosystems, Waltham, MA, USA) on a ViiA 7 Real-Time PCR System (Applied Biosystems, Waltham, MA, USA). For the negative control, we used $20 \mu \mathrm{L}$ of the reaction mixture with no cDNA template. Three technical replicates were prepared for each sample and negative control. Results were normalized for three reference genes, HPRT1 (hypoxanthine phosphoribosyltransferase-1), GAPDH (glyceraldehyde-3-phosphatedehydrogenase), and B2M (beta-2-microglobulin). To assess the effectiveness of PCR, amplification graphs and standard curves were analyzed using QuantStudioTM Real-Time PCR Software v.1.3 (Applied Biosystems). The expression of the studied genes (normalized quantification ratio, NRQ) was calculated by the Pfaffl method and is represented on a logarithmic $(\log 10)$ scale as the fold change relative to control samples [12].

\subsubsection{ELISA}

The concentration of adiponectin, leptin (Human Total Adiponectin/Acro30, DRP300; Human Leptin, DLP00) in the culture medium of adipocytes was determined by ELISA using test systems from R\&D Systems, Inc. (Minneapolis, MN, USA) and IL-6 was determined using the test system Interleukin-6 BMS213-2 from eBioscience (Vienna, Austria).

\subsection{Statistical Analysis}

Statistical analysis was performed using GraphPad Prism 6 (GraphPad Software, La Jolla, CA, USA) and Statistica software, 10.0 (Dell Software, Inc., Round Rock, TX, USA). The Kolmogorov-Smirnov test was used to verify the normal distribution of data. The data were not normally distributed. Therefore, nonparametric methods were used. Data were presented as median (Me) and 25th and 75th quartiles (Q1; Q3). Two independent groups were compared using the Mann-Whitney $U$ test. Three independent groups were compared using the Kruskal-Wallis test by ranks, followed by a pairwise comparison using the nonparametric Mann-Whitney test with the Bonferroni correction. Categorical variables are expressed as percentages and compared using chi-squared test or Fisher's exact test. A $p$-value of less than 0.05 was considered statistically significant. 
To identify the relationship between quantitative indicators and a qualitative trait, the method of stepwise logistic regression analysis and ROC analysis with the construction of the characteristic ROC curve and the calculation of the area under the ROC curve were used. The area under the ROC curve exceeding 0.70 was considered diagnostically significant. Using ROC analysis, the threshold values of the morphometric characteristics of AT of various localization were established.

\section{Results}

3.1. Visualization of Local Fat Depots (Epicardial, Perivascular, Abdominal) in Patients with Coronary Heart Disease

We observed that the thickness of LV EAT and RV EAT was, on average, 1.2 times higher in patients with CAD than in the group of patients with heart defects (Table 2).

Table 2. Indicators of quantitative assessment of epicardial, perivascular, abdominal fat depots in patients with cardiovascular diseases.

\begin{tabular}{|c|c|c|c|}
\hline Parameters & CAD 1, $(n=125)$ & Heart Defects, $(n=120)$ & $p$ \\
\hline Thickness EAT LV, mm & $3.53(2.87 ; 4.36)$ & $2.76(2.42 ; 3.21)$ & $p=0.022$ \\
\hline Thickness EAT RV, mm & $4.58(4.09 ; 6.17)$ & $3.65(3.12 ; 3.97)$ & $p=0.031$ \\
\hline $\begin{array}{c}\text { Thickness PVAT } p / 3 \\
\text { RCA, mm }\end{array}$ & $4.55(3.53 ; 5.76)$ & $2.70(2.41 ; 3.29)$ & $p=0.002$ \\
\hline $\begin{array}{c}\text { Thickness PVAT m/3 } \\
\text { RCA, mm }\end{array}$ & $4.67(3.49 ; 6.13)$ & $2.63(2.24 ; 3.29)$ & $p=0.003$ \\
\hline $\begin{array}{l}\text { Thickness PVAT LCA, } \\
\text { mm }\end{array}$ & $3.64(3.33 ; 4.46)$ & $2.77(2.48 ; 3.12)$ & $p=0.027$ \\
\hline $\begin{array}{c}\text { Thickness PVAT } p / 3 \\
\text { anterior descending } \\
\text { artery, mm }\end{array}$ & $4.31(3.51 ; 4.87)$ & $3.15(2.56 ; 3.03)$ & $p=0.001$ \\
\hline $\begin{array}{c}\text { Thickness PVAT m/3 } \\
\text { anterior descending } \\
\text { artery, } \mathrm{mm}\end{array}$ & $3.71(3.24 ; 4.92)$ & $2.62(2.16 ; 2.88)$ & $p=0.012$ \\
\hline $\begin{array}{l}\text { Thickness PVAT } p / 3 \\
\text { circumflex artery, mm }\end{array}$ & $3.35(3.12 ; 4.47)$ & $2.74(2.34 ; 2.93)$ & $p=0.037$ \\
\hline $\begin{array}{l}\text { Thickness PVAT m/3 } \\
\text { circumflex artery, mm }\end{array}$ & $3.67(3.10 ; 4.99)$ & $2.55(2.27 ; 2.83)$ & $p=0.002$ \\
\hline Area VAT, $\mathrm{cm}^{2}$ & $168.28(149.21 ; 198.19)$ & $136.24(96.28 ; 142.13)$ & $p=0.031$ \\
\hline Area SAT, $\mathrm{cm}^{2}$ & $264.51(190.15 ; 311.46)$ & $277.36(197.12 ; 344.31)$ & $p=0.418$ \\
\hline
\end{tabular}

Notes. The data presented are the medians (25th quartiles and 75th quartiles). EAT, epicardial adipose tissue, LV left ventricle, RV, right ventricle, PVAT, perivascular adipose tissue, $p / 3$, proximal third, RCA, right coronary artery, $\mathrm{m} / 3$, middle third, LCA, left coronary artery, VAT, visceral adipose tissue, SAT, subcutaneous adipose tissue.

In a comparative analysis of the quantitative parameters of PVAT in the study groups of patients with CAD, we observed that the thickness of PVAT of the proximal and middle third of the RCA was higher by $60 \%$ and $75 \%$, respectively, than in patients with heart defects. In patients with CAD, the thickness of the PVAT at the level of the trunk of the left coronary artery (LCA) and the thickness at the level of the proximal and middle third of the RCA were $24 \%, 30 \%$, and 31\% higher, respectively, in comparison with that of group patients with heart defects. There was also an increase in the thickness of the PVAT at the level of the proximal and middle third of the circumflex artery in patients with CAD by $21 \%$ and $30 \%$, respectively, than that of group patients with heart defects. Upon assessing the abdominal fat depot in patients with CAD, we observed that the VAT area exceeded the parameters of patients with heart defects by 1.2 times (Table 2).

The next step was to identify the relationship between the morphometric parameters of AT and the presence of atherosclerosis in the coronary arteries using logistic regression. 
The results are presented in Table 3. We observed that the parameter with the closest association with the presence of atherosclerosis in the coronary arteries is the thickness of the EAT LV, the thickness of the PVAT of the LCA trunk, the proximal third of the anterior descending artery, the proximal third of the circumflex artery, and the area of the VAT.

Table 3. Area under the ROC curve and 95\% confidence interval for atherosclerotic coronary artery disease.

\begin{tabular}{|c|c|c|c|c|}
\hline \multirow{2}{*}{$\begin{array}{c}\text { Parameters } \\
\text { Thickness EAT LV, mm }\end{array}$} & \multirow{2}{*}{$\begin{array}{l}\text { AUC } \\
0.871\end{array}$} & \multirow{2}{*}{$\begin{array}{c}\mathbf{p} \\
p<0.012\end{array}$} & \multicolumn{2}{|c|}{$\begin{array}{l}\text { 95\% Confidence Interval } \\
\text { (CI) }\end{array}$} \\
\hline & & & 0.693 & 0.983 \\
\hline Thickness EAT RV, mm & 0.611 & $p<0.025$ & 0.552 & 0.739 \\
\hline Thickness PVAT $p / 3$ RCA, mm & 0.706 & $p<0.031$ & 0.708 & 0.979 \\
\hline Thickness PVAT m/3 RCA, mm & 0.649 & $p<0.037$ & 0.523 & 0.729 \\
\hline Thickness PVAT LCA, mm & 0.793 & $p<0.022$ & 0.642 & 0.937 \\
\hline $\begin{array}{l}\text { Thickness PVAT } p / 3 \text { anterior } \\
\text { descending artery, mm }\end{array}$ & 0.832 & $p<0.014$ & 0.704 & 0.956 \\
\hline $\begin{array}{c}\text { Thickness PVAT } \mathrm{m} / 3 \text { anterior } \\
\text { descending artery, } \mathrm{mm}\end{array}$ & 0.626 & $p<0.033$ & 0.686 & 0.769 \\
\hline $\begin{array}{c}\text { Thickness PVAT } p / 3 \text { circumflex } \\
\text { artery, mm }\end{array}$ & 0.771 & $p<0.019$ & 0.631 & 0.847 \\
\hline $\begin{array}{l}\text { Thickness PVAT } \mathrm{m} / 3 \\
\text { circumflex artery, } \mathrm{mm}\end{array}$ & 0.611 & $p<0.041$ & 0.556 & 0.718 \\
\hline Area VAT, $\mathrm{cm}^{2}$ & 0.809 & $p<0.026$ & 0.694 & 0.963 \\
\hline Area SAT, $\mathrm{cm}^{2}$ & 0.598 & $p<0.035$ & 0.386 & 0.627 \\
\hline
\end{tabular}

EAT, epicardial adipose tissue; LV, left ventricle; RV, right ventricle; PVAT, perivascular adipose tissue; $p / 3$, proximal third, RCA, right coronary artery; $\mathrm{m} / 3$, middle third, LCA, left coronary artery; VAT, visceral adipose tissue; SAT, subcutaneous adipose tissue; AUG, area under the ROC curve.

Threshold values were set for quantitative indicators of fat storage most associated with coronary atherosclerosis. Thus, for the thickness of the EAT LV, this parameter was $3.3 \mathrm{~mm}$ (sensitivity $=87.4$, specificity $=88.9$ ) for the thickness of the PVAT LCA was $3.4 \mathrm{~mm}$ (sensitivity $=86.4$, specificity $=87.2$ ), $p / 3$ anterior descending artery was $3.7 \mathrm{~mm}$ (sensitivity $=88.3$, specificity $=87.5$ ), and $p / 3$ circumflex artery was $3.35 \mathrm{~mm}$ (sensitivity $=86.4$, specificity $=88.1)$ ). The critical level of the VAT area was $106.1 \mathrm{~cm}^{2}$ (sensitivity $=90.9$, specificity $=89.2$ ).

\subsection{Adiponectin Gene Expression and Concentration of Adiponectin in the Daily Adipocyte} Culture of Various Fat Depots

Adipocytes in the EAT expressed the lowest amount of ADIPOQ relative to adipocytes in different locations in both groups (Figure 3a).

In patients with CAD, ADIPOQ expression in the EAT was significantly lower than in the culture of SAT and PVAT (1.2 times $(p=0.038)$ and 1.5 times $(p=0.027)$, respectively). Similarly, in group patients with aortic or mitral valve replacement, ADIPOQ expression in EAT adipocytes was lower compared to adipocytes in the SAT and PVAT (1.4 times $(p=0.001)$ and 1.5 times $(p=0.002)$, respectively). Moreover, in Group 2, the mRNA level of $A D I P O Q$ in EAT adipocytes was higher than that of patients with CAD by 1.2 times $(p=0.031)$. High mRNA levels of ADIPOQ were observed in the culture of PVAT. Further, $A D I P O Q$ expression in cultures of SAT and PVAT adipocytes was not statistically different between patients with CAD and heart defects (Figure 1). 

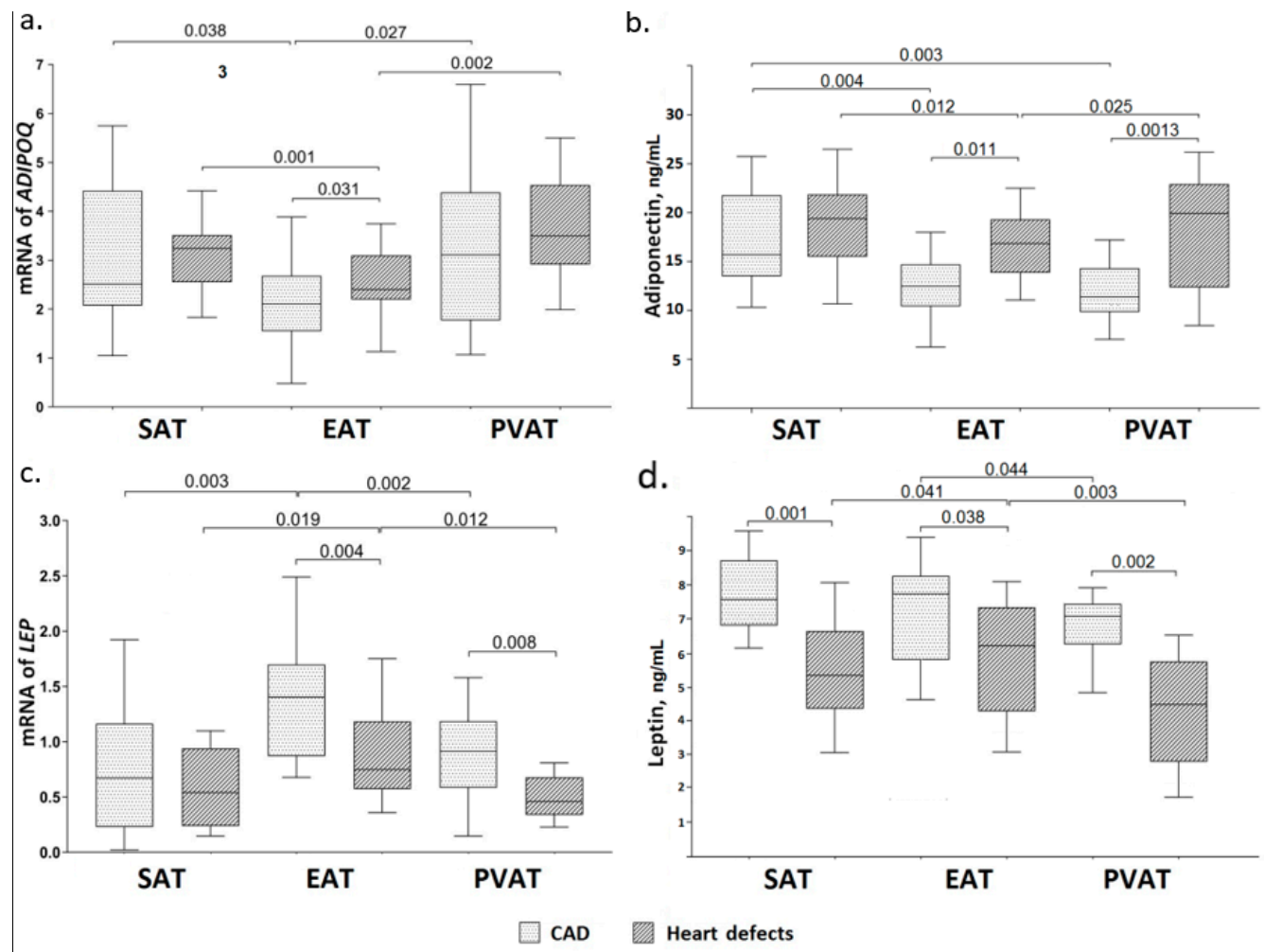

Figure 3. Adipokine gene expression and secretion in various fat depots in the daily culture of adipocytes derived from patients with CAD and patients with heart defects (aortic or mitral valve replacement). (a) Adiponectin gene expression (b) Adiponectin concentration (c) Leptin gene expression (d) Leptin concentration Notes: ADIPOQ-gene of adiponectin, LEP-gene of leptin, CAD-patients with coronary artery disease and those with indications of direct myocardial revascularization by coronary artery bypass grafting, Heart defects patients with aortic or mitral valve replacement, $p$-significant differences as compared to subcutaneous adipocytes, $(p \leq 0.05)$.

The concentration of adiponectin in the daily culture of EAT adipocytes was lower than that of SAT in both groups ( 1.3 times $(p=0.004)$ and 1.13 times $(p=0.012)$, respectively) (Figure $3 b$ ).

Moreover, adiponectin levels in group with heart defects were 1.4 times higher than in group patients with CAD individuals $(p=0.011)$. The lowest level of adiponectin secretion was detected in PVAT adipocytes of patients with CAD than that of adipocyte cultures at different locations. By contrast, in patients heart defects, adiponectin levels in the PVAT exceeded that of fat depots at different locations by 1.8 times $(p=0.001)$. Adiponectin concentrations in cultures of SAT adipocytes were not statistically different between groups patients with CAD and heart defects (Figure $3 b$ ).

\subsection{Leptin Gene Expression and Concentration of Leptin in the Daily Adipocyte Culture of Various Fat Depots}

High levels of $L E P$ expression were observed in the culture of EAT adipocytes in patients of both groups compared with adipocytes at a different location (Figure 3c). In group patients with CAD, $L E P$ expression was 1.9 times higher than in group with heart defects $(p=0.004)$. Thus, mRNA levels of the LEP gene in EAT adipocytes exceeded that of the SAT and PVAT adipocytes by $2.1(p=0.003)$ and 1.5 times $(p=0.002)$, respectively, among patients with CAD, and by $1.4(p=0.019)$ and 1.6 times $(p=0.012)$, respectively, in patients with heart defects. Moreover, in group patients with heart defects, the lowest mRNA level of the LEP was detected in the PVAT culture, which was two times $(p=0.008)$ lower than that in patients with CAD. However, LEP expression in SAT adipocyte cultures did not show a statistically significant difference, independent of nosology (Figure 3c). 
Leptin concentration was also the highest in the culture of EAT adipocytes in both groups, whereas among patients with CAD, it exceeded that group of heart defects by 1.2 times $(p=0.038)$ (Figure $3 \mathrm{~d}$ ). However, statistically significant differences compared with SAT were only found in individuals of patients with heart defects (1.2 times, $p=0.041)$. The lowest leptin concentration was observed in PVAT adipocytes compared to adipocyte cultures of other locations, and statistically significant differences were found relative to EAT adipocytes. Leptin levels in the PVAT were 1.1 times $(p=0.044)$ lower than that of the EAT in group patients with CAD and 1.5 times $(p=0.003)$ lower than that of group with heart defects. Further, leptin concentration in the PVAT adipocyte supernatant of patients with CAD was 1.5 times higher than that of comparison group $(p=0.002)$. There were no statistically significant differences in leptin concentration in the culture of SAT adipocytes between groups (Figure 3d).

\subsection{IL-6 Gene Expression and Concentration of IL-6 in the Daily Adipocyte Culture of Various Fat Depots}

Upon measuring pro-inflammatory IL6 expression in a $24 \mathrm{~h}$ culture of adipocytes at various locations, maximum levels were observed in the EAT relative to the SAT and PVAT in group patients with CAD (2.1 times with $p=0.0012$ and 1.4 times with $p=0.0024$, respectively) and comparison group relative to the PVAT (1.9 times with $p=0.0002$ ). Moreover, mRNA level of the IL6 in the EAT of patients with CAD exceeded that of group patients with heart defects by 1.4 times $(p=0.0013)$ (Table 4$)$. Further, IL6 expression in PVAT adipocytes in group patients with CAD was 1.9 times $(p=0.0001)$ higher than that of patients with heart defects. Subcutaneous adipocytes in both groups did not show differences in IL-6 gene expression.

Table 4. Gene expression IL-6 and IL-6 concentration in adipocyte cultures of various fat depots in patients with coronary artery disease and patients with aortic or mitral valve replacement.

\begin{tabular}{|c|c|c|c|c|c|c|c|c|}
\hline \multirow{3}{*}{ Parameter } & \multicolumn{2}{|c|}{ Subcutaneous Adipocytes } & \multicolumn{2}{|c|}{ Epicardial Adipocytes } & \multicolumn{2}{|c|}{ Perivascular Adipocytes } & & \multirow{3}{*}{$p$} \\
\hline & CAD & Heart Defects & CAD & $\begin{array}{c}\text { Heart } \\
\text { Defects }\end{array}$ & CAD & $\begin{array}{c}\text { Heart } \\
\text { Defects }\end{array}$ & & \\
\hline & 1 & 2 & 3 & 4 & 5 & 6 & & \\
\hline \multirow{2}{*}{$\begin{array}{c}\text { IL6 expression, } \\
\text { Delta } \mathrm{Ct}\end{array}$} & $\begin{array}{c}0.037 \\
(0.025 ; 0.051)\end{array}$ & $\begin{array}{c}0.053 \\
(0.034 ; 0.061)\end{array}$ & $\begin{array}{c}0.077 \\
(0.062 ; 0.081)\end{array}$ & $\begin{array}{c}0.056 \\
(0.049 ; 0.075)\end{array}$ & $\begin{array}{c}0.048 \\
(0.037 ; 0.057)\end{array}$ & $\begin{array}{c}0.029 \\
(0.021 ; 0.032)\end{array}$ & \multirow[t]{2}{*}{0.012} & $\begin{array}{l}P_{1-3}=0.003 \\
P_{3-5}=0.011\end{array}$ \\
\hline & \multicolumn{2}{|c|}{$P_{1-2}=0.124$} & \multicolumn{2}{|c|}{$P_{3-4}=0.002$} & \multicolumn{2}{|c|}{$P_{5-6}=0.0002$} & & $\mathrm{P}_{4-6}=0.0001$ \\
\hline \multirow[t]{2}{*}{$\mathrm{IL}-6, \mathrm{pg} / \mathrm{mL}$} & $\begin{array}{c}12.37 \\
(9.12 ; 16.27)\end{array}$ & $\begin{array}{c}13.92 \\
(10.01 ; 16.26)\end{array}$ & $\begin{array}{c}29.35 \\
(25.18 ; 37.16)\end{array}$ & $\begin{array}{c}21.55 \\
(17.77 ; 23.34)\end{array}$ & $\begin{array}{c}18.12 \\
(15.61 ; 21.06)\end{array}$ & $\begin{array}{c}11.64 \\
(8.79 ; 14.17)\end{array}$ & \multirow[t]{2}{*}{0.011} & $\begin{array}{l}P_{1-3}=0.0001 \\
P_{3-5}=0.0002\end{array}$ \\
\hline & $P_{1-2}$ & 0.071 & $\mathrm{P}_{3-4}$ & 0.022 & $P_{5-6}$ & 0.025 & & $\begin{array}{l}\mathrm{P}_{2-4}=0.022 \\
\mathrm{P}_{4-6}=0.001\end{array}$ \\
\hline
\end{tabular}

The data presented are the medians (25th quartiles, 75th quartiles). IL6, interleukin-6 gene, IL-6, interleukin-6.

The concentration of IL-6 in the EAT adipocyte culture was higher compared to SFU and PVAT, regardless of nosology (Table 4). Thus, in patients with CAD, the concentration of IL- 6 in the EAT was 2.5 times and 1.8 times higher than that in the SAT and PVAT, respectively. In Group 2, the EAT was 1.5 times and 1.8 times higher than that in the SAT and PVAT, respectively. Moreover, the concentration of IL- 6 in the EAT and PVAT in patients with CAD exceeded the level of patients with heart defects by 1.4 times $(p=0.022$ and $p=0.018$, respectively). IL-6 secretion in SAT adipocytes did not differ between groups.

3.5. Relationship between Gene Expression and Secretion of Adipocytokines in AT with Indicators of Morphometric Characteristics of Local Fat Depots of the Heart and Blood Vessels in Patients with $C A D$

Patients with CAD were divided into groups in accordance with the threshold values of the size of fat depots to identify the factors most associated with the expression and secretion of adipocytokines and morphometric characteristics of AT of ectopic localization. For example, the number of patients in whom the values of the thickness of the EAT LV, 
PVAT LCA, $p / 3$ anterior descending artery, $p / 3$ circumflex artery, and the area of the VAT exceeded the threshold values amounted to 60 (48\%).

Among all the studied indicators of adipocytokine status, the expression of $A D I P O Q$ in the EAT and PVAT, LEP in the EAT, IL6 in the EAT and PVAT, the concentration of adiponectin in the EAT, and leptin in the EAT and PVAT were most associated with an increase in the size of local fat depots (Table 5).

Table 5. Association of the level of expression and secretion of adipocytokines from local fat depots with an increase in morphometric parameters of adipose tissues in patients with CAD.

\begin{tabular}{ccccc}
\hline Parameters & $\begin{array}{c}\text { Odds Ratio } \\
(\mathbf{O R})\end{array}$ & \multicolumn{2}{c}{$\begin{array}{c}\text { 95\% Confidence } \\
\text { Interval (CI) }\end{array}$} & $p$ \\
\hline ADIPOQ expression in EAT & 0.47 & 0.39 & 0.53 & $p=0.013$ \\
\hline ADIPOQ expression in PVAT & 0.63 & 0.55 & 0.71 & $p=0.002$ \\
\hline LEP expression in EAT & 1.54 & 1.44 & 1.60 & $p=0.022$ \\
\hline IL6 expression in EAT & 1.51 & 1.43 & 1.59 & $p=0.002$ \\
\hline IL6 expression in PVAT & 1.41 & 1.35 & 1.50 & $p=0.002$ \\
\hline Adiponectin concentration in EAT & 0.55 & 0.46 & 0.61 & $p=0.001$ \\
\hline Leptin concentration in EAT & 2.52 & 2.46 & 2.60 & $p=0.014$ \\
\hline Leptin concentration in PVAT & 2.34 & 2.25 & 2.40 & $p=0.001$ \\
\hline IL-6 concentration in EAT & 1.49 & 1.40 & 1.58 & $p=0.002$ \\
\hline
\end{tabular}

\section{Discussion}

Recently, AT of the heart and blood vessels has been gaining attention as a new modifiable risk factor for the development and progression of CVD [13,14]. At the same time, it is well known that AT performs a number of key functions necessary for maintaining tissue and cellular myocardial homeostasis [15]. The dualism of the physiological and pathological effects of AT a given site is not fully understood, although it has been noted that an unfavorable course of CVD is associated with AT dysfunction in the heart and blood vessels. Further, fat deposits around the heart and blood vessels can play an important role in the pathogenesis of CVD owing to their anatomical proximity to vascular structures and the myocardium. It has been proven that the paracrine effect of PVAT on the vascular wall consists of the secretion of adipocytokines involved in vasoconstriction and vasodilation [16]. Moreover, adipocytes secrete adipokines and proinflammatory cytokines' the level of the secretion is known to correlate with obesity [17].

One of the objectives of this study was a comparative assessment of the morphometric parameters of EAT in patients with coronary and non-coronary heart disease. The results obtained indicate that patients with CAD exhibited higher values of EAT thickness along the anterior wall of the RV, which indicates an uneven distribution of EAT along the heart surfaces. These features are presumably anatomically and physiologically determined. It has previously been shown that the left and right ventricles contain the same absolute amount of fat on their epicardial surfaces [18]. However, taking into account the obvious differences in the mass of the myocardium of the respective ventricles, the proportion of $\mathrm{AT}$ in the left ventricle was less than in the right one. At the same time, the maximum EAT thickness was observed in patients with CAD. According to Iantorno et al., an increase in the linear indicators of EAT was observed in patients with CAD and immunodeficiency in comparison with persons with no signs of CAD [(13.9 $\pm 3.1 \mathrm{~mm})$ and $(10.7 \pm 3.3)$ $\mathrm{mm}$, respectively $(p=0.001)$ ] [19]. Similar results were obtained by Picard et al., who reported that the thickness of EAT in patients with CAD was $2.74 \pm 2.4 \mathrm{~mm}$, whereas it was $(2.08 \pm 2.1) \mathrm{mm}(p=0.0001)$ in healthy individuals [20]. An increase in the size of EAT in patients with CAD may be due to a low level of AT oxygenation due to impaired blood supply to the myocardium in coronary heart disease (AT of the heart is in general 
circulation with the myocardium). Previous studies have found an inverse relationship between adipocyte size and AT blood flow [21].

Statin therapy plays an important role in the primary and secondary prevention of cardiovascular disease. In addition to inhibiting $\beta$-hydroxy $\beta$-methylglutaryl-CoA reductase, statins can interfere with various processes such as signaling, differentiation, and cell proliferation. The modulation of EAT by statins may be one of the most important pleiotropic effects of this class of drugs. One study has also suggested a potential antiinflammatory effect of statins on VAT, [22]. However, there is little evidence of an effect on VAT in the cardiac region.

Indeed, there are positive results from studies conducted for different durations. In the study by Alexopoulos, statin therapy for 12 months resulted in a decrease in EAT compared with placebo [23]. In a relatively recent study, intensive statin therapy for patients with CAD when used for 3 to 72 months also indicates a direct effect on EAT thickness (assessed by ECHO-CT) and inflammatory status [24].

In the experimental study by Ishihara, treatment of 3T3-L1 preadipocytes with different concentrations of pitavastatin and the daily administration of the drug to female mice showed that statins significantly reduce (by $16.8 \%$ ) the number of hypertrophied adipocytes, the total mass of which remained unchanged [25]. Later, in another pilot study, it was similarly demonstrated that low concentrations of statins $(10 \mathrm{mg} / \mathrm{kg}$ atorvastatin and $3 \mathrm{mg} / \mathrm{kg}$ rosuvastatin for 48 days) consistently reduce AT mass and adipocyte size in mice on a high-fat diet [26].

Thus, statins are undoubtedly potential drugs capable of directly affecting the AT of the heart and modulating the functional activity and size of adipocytes; however, for the manifestation of these effects, their long-term use from several months to 1 year is required. In our study, patients took statins for 5 days before CABG and, therefore, before receiving VT biopsies. Additionally, the measurement of the morphometric parameters of fat depots was carried out in the period from 1 to 4 days before the operation; therefore, we assume that statin therapy in our case could not significantly affect the results of the study.

This study also showed that there was an increase in the thickness of the PVAT at the level of the proximal and middle third of the RCA, the proximal and middle thirds of the LAD and CX, as well as the trunk of the LCA in patients with CAD, compared with patients with heart defects. Thus, there is a significant predominance of PVAT in the basin of the RCA. The data obtained are consistent with the results of the study by Demircelk et al. The average thickness of the PVAT was significantly higher in patients with signs of obstructive atherosclerotic lesions in comparison with those with no signs of CAD and minor signs of coronary atherosclerosis [27].

An increase in the PVAT indices in patients with CAD may be due to mechanisms similar to that operating in the EAT. A decrease in oxygen supply against the background of atherosclerotic lesions of the coronary arteries can affect the pericoronary AT, causing hypoxia, and leading to an increase in the size of adipocytes. In addition, studies conducted in recent decades have shown the participation of adventitia and the surrounding PVAT in the development of atherosclerosis in the coronary arteries [28].

The identified associations may be associated with an increase in the secretory activity of cardiac and vascular AT in patients with CAD. Previously, it was shown that the adipocytes of EAT and PVAT are characterized by impaired differentiation and disproportionate adipocytokine secretion, manifested by a decrease in adiponectin levels and an increase in leptin and IL-6 levels in comparison with adipocytes of SAT and perirenal adipocytes [29]. According to our results, adiponectin gene expression levels in the culture of EAT adipocytes was the lowest in patients of both groups. In addition, the level of adiponectin in the EAT and PVAT is associated with an increase in the size of local fat depots around the heart and blood vessels. The data obtained in our study is consistent with the study of Bambacea et al. [6]. and Iacobellis at al [30]. In a study by Eiras at al., a reduced mRNA level of the $A D I P O Q$ detected in the EAT relative to the SAT in patients without CAD [31]. However, other authors have shown no differences between 
patients with CAD and patients with aortic or mitral valve replacement. For example, Iglesias et al. showed that adiponectin gene expression in the EAT was lower than in the SAT, but there were no statistically significant differences between patients after CABG and with valve replacement [32]. The authors explain this by gender characteristics, as mRNA level of the ADIPOQ in the EAT were higher in women. PVAT is also actively involved in atherogenesis, and it synthesizes proinflammatory molecules that are involved in the formation of unstable plaques that are prone to rupture and atherothrombosis and promote the progression of CAD $[8,33]$. Due to this close interaction, the PVAT is the first fat depot that recognizes and reacts to emerging changes in homeostasis through the synthesis and production of adipocytokines [34]. Adiponectin plays a crucial role, as its protective and anti-inflammatory properties are known. Our results demonstrate that PVAT had the highest level of adiponectin gene expression. Moreover, adiponectin was higher in group patients with heart defects. Similar data were demonstrated by Cybularz et al. [35]. Reduced adiponectin gene expression in combination with high expression of the leptin gene may be associated with the activation of key atherogenic pathways, contributing to the progression of CAD [36].

Based on the literature, it can be assumed that the levels of adipocytokine mRNA in the AT are not always a complete reflection of their concentration [37]. In this study, PVAT adipocytes of patients with CAD were characterized by the highest level of adiponectin gene expression, yet they exhibited the lowest concentration in the culture supernatants compared to adipocyte cultures at other locations. One of the reasons for this difference may be the low expression of adiponectin receptors in these fat depots. In a study by Guo at al., which assessed the role of adiponectin and its receptors in vivo, the authors found that angiotensin II (Ang II)-induced hypertension led to a significant decrease in the expression of both adiponectin and its AdipoR1 and AdipoR2 receptors in perivascular adipocytes and vascular cells [38]. Nacci et al. investigated the effect of infliximab on adiponectin gene expression in PVAT and showed a decrease in the level of adiponectin mRNA, AdipoR1, and AdipoR2 in mice with type 1 DM. Taken together, the findings suggest that the PVAT is a site of adiponectin/AdipoR dysregulation, and secondly, it is most susceptible to proinflammatory signals [39].

Another reason may be the long-term processes of post-translational modification and oligomerization of adiponectin. The observed high level of adiponectin in PVAT is due to the longer processes of "maturation" of adiponectin in CAD, which occur in the endoplasmic reticulum (ER) of adipocytes and are controlled by special proteins/chaperones in the ER such as Ero1-L $\alpha$. It is assumed that part of the synthesized adiponectin undergoes decay or proteolysis, and the delayed release of adiponectin is due to disruption of proteinchaperones that regulate adiponectin secretion from the cell [40]. In addition, Bauchea et al. showed that adiponectin was to be able to suppress its own production and expression of its AdipoR2 receptor in transgenic mice [41]. Further, Kadowaki et al. demonstrated a decrease in the number of adiponectin receptors in metabolic syndrome and obesity [42].

Leptin, the most studied adipokine marker of obesity, participates in the regulation of atherogenesis, thrombogenesis, and vascular revascularization. Further, it stimulates inflammatory processes, oxidative stress, and vascular smooth muscle cell hypertrophy. Leptin plays a role in the pathogenesis of hypertension, CAD, and type 2 DM and the development of their complications [43]. According to our data, a higher expression of the leptin gene was observed in the culture of EAT adipocytes compared to the SAT in patients. Furthermore, in patients with CAD, LEP expression was the highest in PVAT adipocytes. An increase in the level of LEP expression in EFT is associated with an increase in the size of fat depots in the heart and around the coronary vessels. This data is consistent with the data provided by other groups [44]. Polyakova et al. showed that in men, regardless of the presence of coronary heart disease, the LEP expression in the EAT was significantly higher than the SAT [45]. Furthermore, the authors explain the observed differences by the predominance of men among patients with CAD, and the incidence of more severe atherosclerotic lesions of the coronary arteries in male patients [46]. However, Iglesias et al. 
showed that $L E P$ expression in the EAT was lower than the SAT from 46 patients who were undergoing heart surgery, coronary artery bypass surgery, or aortic or mitral valve replacement. Moreover, leptin mRNA expression in EAT was higher in women than men [32]. Increased leptin gene expression in the EAT culture of patients can have a negative effect on both adipocytes and cardiomyocytes by activating inflammatory and atherosclerotic processes [47].

Thus, the "protective" potential of AT depends on its localization. EFT adipocytes of CAD patients are characterized by changes in the adipocytokine system: low level of adiponectin gene expression against a high level of leptin gene expression and secretion compared to adipocytes at other locations.

IL-6 has been shown to produce various types of cells. However, adipocytes are also able to secrete proinflammatory IL-6 [48]. Approximately $30 \%$ of the IL-6 in the body is synthesized by AT, and its production is increased in overweight individuals. IL-6 is involved in the regulation of the energy balance of fat and muscle tissues, triggering regenerative mechanisms of immune protection and regulation of fat intake into AT. In addition, IL-6 is able to limit the inflammatory response by inhibiting the synthesis of a number of proinflammatory cytokines, including tumor necrosis factor- $\alpha$ (TNF- $\alpha$ ) [49]. In vitro studies have shown that isolated visceral fat synthesizes more IL-6 than subcutaneous fat, and increased IL-6 production has been observed in adipocyte hypertrophy. plasma levels of IL- 6 correlate with the area of epicardial and abdominal visceral AT in patients with coronary artery atherosclerosis, suggesting a potential effect of these fat depots on the development of atherosclerosis through paracrine rather than systemic effects [14].

We found that IL6 expression in the daily culture of EAT adipocytes was the highest in comparison to the SAT and PVAT in both patients with CAD and those with aortic or mitral valve replacement. Moreover, the level of IL6 mRNA in the EAT and PVAT in individuals with CAD was higher than in patients with heart defects. These identified features are consistent other studies. Shibasaki at al. found that IL6 expression in the EAT was significantly higher than that in the SAT [50]. Moreover, IL6 and LEP expression in the EAT was higher in patients with CAD, and $A D I P O Q$ expression were comparable in both groups. In the SAT, IL6 and LEP expression levels were moderately higher in patients with $C A D$ compared to those without CAD. However, there were no differences in plasma cytokine levels between the two groups. [50].

Increased IL6 expression and secretion in EAT and PVAT adipocytes can contribute to the high level of $L E P$ expression and content observed in these types of AT. It is known that leptin has a stimulating effect on immune cells and is able to regulate the production of proand anti-inflammatory cytokines. [51]. In addition, some studies have noted homology in the structure of leptin and IL-6 receptors, also suggesting an interaction between leptin and circulating factors, through which cytokines inhibit binding of the leptin receptor to block its signaling activity in cell culture [52].

Experimental in vitro findings demonstrated that secretory products of adipocytes increase the secretion of inflammatory cytokines by macrophages and other immune cells, and pro-inflammatory cytokines, in particular IL-6, increase the transcription of leptin, which was confirmed by in vivo studies. Pro-inflammatory stimuli such as TNF- $\alpha$ and IL-6 itself can enhance IL-6 production in vitro. The content of IL-6 in AT is hundred times higher than in the plasma, suggesting important auto and paracrine regulatory functions in this tissue [53].

\section{Conclusions}

In conclusion, increased production of leptin and IL-6 and decreased production of cardioprotective adiponectin led to activation of immune cells and inflammation. This manifested primarily in EAT and PVAT adipocytes, especially in individuals with CAD, which creates favorable conditions for the development and progression of atherosclerosis. Moreover, leptin is able to affect the vascular wall and activate platelet aggregation, increasing the risk of thrombosis. Established changes in the content of the studied adipocy- 
tokines in epicardial adipocytes is a prognostically unfavorable sign in this category of patients. Therefore, the study of EAT revealed the pathogenetic significance of changes in the adipokine and cytokine status of adipocytes in patients with CAD.

Author Contributions: Conceptualization, O.V.G.; data curation, O.V.G., O.L.B.; formal analysis Y.A.D., E.V.B., E.E.B.; investigation Y.A.D., E.V.B., M.Y.S., N.K.B., E.E.B., E.O.K.; methodology, O.V.G., Y.A.D., A.N.K., R.S.T.; administration, O.L.B.; resources, A.N.S.; supervision, O.L.B.; validation, O.V.G.; writing - original draft preparation, O.V.G., Y.A.D., E.V.B.; writing—review and editing, O.V.G., Y.A.D. All authors have read and agreed to the published version of the manuscript.

Funding: This research is conducted within the fundamental research project No. 0546-2015-0012 "Multivessel coronary artery disease, polyvascular disease and comorbid conditions. The diagnosis and risk management in a large industrial region of Siberia" (Principal Investigator-director of the NII KPSSZ, M.D., Ph.D., Prof., Barbarash O.L.).

Institutional Review Board Statement: The study was performed at the Federal State Budgetary Institution's Research Institute for Complex Issues of Cardiovascular Diseases. The study protocol No. 1 from 4.02.2020 was approved by the Local Ethics Committee of the Federal State Budgetary Institution Research Institute for Complex Issues of Cardiovascular Diseases and was developed according to the World Medical Association's Declaration of Helsinki on Ethical Principles for Medical Research Involving Human Subjects, 2000 edition, and the "GCP Principles in the Russian Federation", approved by the Russian Ministry of Health.

Informed Consent Statement: Informed consent was obtained from all subjects involved in the study.

Conflicts of Interest: The authors declare no conflict of interest.

\section{References}

1. Nakamura, K.; Fuster, J.J.; Walsh, K. Adipokines: A link between obesity and cardiovascular disease. J. Cardiol. 2014, 63, 250-259. [CrossRef]

2. Tanaka, K.; Fukuda, D.; Sata, M. Roles of epicardial adipose tissue in the pathogenesis of coronary atherosclerosis-An update on recent findings. Circ. J. 2020, 85, 2-8. [CrossRef]

3. Bambace, C.; Sepe, A.; Zoico, E.; Telesca, M.; Olioso, D.; Venturi, S.; Rossi, A.; Corzato, F.; Faccioli, S.; Cominacini, L.; et al. Inflammatory profile in subcutaneous and epicardial adipose tissue in men with and without diabetes. Heart Vessels 2014, 29, 42-48. [CrossRef]

4. Anthony, S.R.; Guarnieri, A.R.; Gozdiff, A.; Helsley, R.N.; Owens, A.P., III; Tranter, M. Mechanisms linking adipose tissue inflammation to cardiac hypertrophy and fibrosis. Clin. Sci. 2019, 133, 2329-2344. [CrossRef]

5. Mahabadi, A.A.; Berg, M.H.; Lehmann, N.; Kalsch, H.; Bauer, M.; Kara, K.; Dragano, N.; Moebus, S.; Jockel, K.H.; Erbel, R.; et al. Association of epicardial fat with cardiovascular risk factors and incident myocardial infarction in the general population. J. Am. Coll. Cardiol. 2013, 61, 1388-1395. [CrossRef]

6. Bambacea, C.; Telescab, M.; Zoicoa, E.; Sepe, A.; Olioso, D.; Rossi, A.; Corzato, F.; Di Francesco, V.; Mazzucco, A.; Santini, F.; et al. Adiponectin gene expression and adipocyte diameter: A comparison between epicardial and subcutaneous AT in men. Cardiovasc. Pathol. 2011, 20, e153-e156. [CrossRef]

7. Lehr, S.; Hartwig, S.; Lamers, D.; Famulla, S.; Muller, S.; Hanisch, F.G.; Cuvelier, C.; Ruige, J.; Eckardt, K.; Ouwens, D.M.; et al. Identification and validation of novel adipokines released from primary human adipocytes. Mol. Cell Proteom. 2012, 11, M111.010504. [CrossRef]

8. Verhagen, S.N.; Visseren, F.L. Perivascular AT as a cause of atherosclerosis. Atherosclerosis 2011, 214, 3-10. [CrossRef]

9. Gruzdeva, O.V.; Dyleva, Y.A.; Antonova, L.V.; Matveeva, V.G.; Uchasova, E.G.; Fanaskova, E.V.; Karetnikova, V.N.; Ivanov, S.V.; Barbarash, O.L. Adipokine and cytokine profiles of epicardial and subcutaneous at in patients with coronary heart disease. Bull. Exp. Biol. Med. 2017, 163, 608-611. [CrossRef]

10. Suga, H.; Matsumoto, D.; Inoue, K.; Shigeura, T.; Eto, H.; Aoi, N.; Kato, H.; Abe, H.; Yoshimura, K. Numerical Measurement of Viable and Nonviable Adipocytes and Other Cellular Components in Aspirated Fat Tissue. Plast. Reconstr. Surg. 2008, 122, 103-114. [CrossRef]

11. Sinitsky, M.Y.; Dyleva, Y.A.; Uchasova, E.G.; Belik, E.V.; Yuzhalin, A.E.; Gruzdeva, O.V.; Matveeva, V.G.; Ponasenko, A.V. Adipokine gene expression in adipocytes isolated from different fat depots of coronary artery disease patients. Arch. Physiol. Biochem. 2019, 1-9. [CrossRef]

12. Pfaffl, M.W. A new mathematical model for relative quantification in real-time RT-PCR. Nucleic Acids Res. 2001, 29, e45. [CrossRef]

13. Mookadam, F.; Goel, R.; Alharthi, M.S.; Jiamsripong, P.; Cha, S. Epicardial fat and its association with cardiovascular risk: A cross-sectional observational study. Heart Views 2010, 11, 103. 
14. Chu, C.Y.; Lee, W.H.; Hsu, P.C.; Lee, M.K.; Lee, H.H.; Chiu, C.A.; Lin, T.H.; Lee, C.S.; Yen, H.W.; Voon, W.C.; et al. Association of Increased Epicardial Adipose Tissue Thickness With Adverse Cardiovascular Outcomes in Patients With Atrial Fibrillation. Medicine 2016, 95, e2874. [CrossRef]

15. Guglielmi, V.; Sbraccia, P. Epicardial adipose tissue: At the heart of the obesity complications. Acta Diabetol. 2017, 54, 805-812. [CrossRef]

16. Ben-Zvi, D.; Savion, N.; Kolodgie, F.; Simon, A.; Fisch, S.; Schafer, K.; Bachner-Hinenzon, N.; Cao, X.; Gertler, A.; Solomon, G.; et al. Local application of leptin antagonist attenuates angiotensin ii-induced ascending aortic aneurysm and cardiac remodeling. J. Am. Heart Assoc. 2016, 5, e003474. [CrossRef]

17. Trayhurn, P.; Wood, I.S. Signalling role of AT: Adipokines and inflammation in obesity. Biochem. Soc. Trans. 2005, 33, 1078-1081. [CrossRef]

18. Corradi, D.; Maestri, R.; Callegari, S.; Pastori, P.; Goldoni, M.; Luong, T.V.; Bordi, C. The ventricular epicardial fat is related to the myocardial mass in normal, ischemic and hypertrophic hearts. Cardiovasc. Pathol. 2004, 13, 313-316. [CrossRef]

19. Iantorno, M.; Soleimanifard, S.; Schar, M.; Brown, T.T.; Bonanno, G.; Barditch-Crovo, P.; Mathews, L.; Lai, S.; Gerstenblith, G.; Weiss, R.G.; et al. Regional coronary endothelial dysfunction is related to the degree of local epicardial fat in people with HIV. Atherosclerosis 2018, 278, 7-14. [CrossRef]

20. Picard, F.A.; Gueret, P.; Laissy, J.P.; Champagne, S.; Leclercq, F.; Carrie, D.; Juliard, J.M.; Henry, P.; Niarra, R.; Chatellier, G.; et al. Epicardial adipose tissue thickness correlates with the presence and severity of angiographic coronary artery disease in stable patients with chest pain. PLOS ONE 2014, 9, e110005. [CrossRef]

21. Trayhurn, P. Hypoxia and adipose tissue function and dysfunction in obesity. Physiol. Rev. 2013, 93, 1-21. [CrossRef] [PubMed]

22. Labuzek, K.; Bułdak, L.; Duława-Bułdak, A.; Bielecka, A.; Krysiak, R.; Madej, A.; Okopien, B. Atorvastatin and fenofibric acid differentially affect the release of adipokines in the visceral and subcutaneous cultures of adipocytes that were obtained from patients with and without mixed dyslipidemia. Pharmacol. Rep. 2011, 63, 1124-1136. [CrossRef]

23. Alexopoulos, N.; Melek, B.H.; Arepalli, C.D.; Hartlage, G.R.; Chen, Z.; Kim, S.; Raggi, E.S.P. Effect of intensive versus moderate lipid-lowering therapy on epicardial adipose tissue in hyperlipidemic post-menopausal women: A substudy of the BELLES Trial (Beyond endorsed lipid lowering with EBT scanning). JACC 2013, 61, 1956-1961. [CrossRef]

24. Parisi, V.; Petraglia, L.; D’Esposito, V.; Cabaro, S.; Rengo, G.; Caruso, A.; Grimaldi, M.G.; Baldascino, F.; De Bellis, A.; Vitale, D.; et al. Statin therapy modulates thickness and inflammatory profile of human epicardial adipose tissue. Int. J. Cardiol. 2019, 274, 326-330. [CrossRef]

25. Ishihara, Y.; Ohmori, K.; Mizukawa, M.; Hasan, A.U.; Noma, T.; Kohno, M. Beneficial direct adipotropic actions of pitavastatin in vitro and their manifestations in obese mice. Atherosclerosis 2010, 212, 131-138. [CrossRef]

26. Lee, S.; Lee, Y.; Kim, J.; An, J.; Kim, K.; Lee, H.; Kong, H.; Song, Y.; Kim, K. Atorvastatin and rosuvastatin improve physiological parameters and alleviate immune dysfunction in metabolic disorders. Biochem. Biophys. Res. Commun. 2016, 478, $1242-1247$. [CrossRef]

27. Demircelik, M.B.; Yilmaz, O.C.; Gurel, O.M.; Selcoki, Y. Epicardial adipose tissue and pericoronary fat thickness measured with 64-multidetector computed tomography: Potential predictors of the severity of coronary artery disease. Clinics 2014, 69, 388-392. [CrossRef]

28. Kolodgie, F.D.; Virmani, R.; Cornhill, J.F.; Herderick, E.E.; Smialek, J. Increase in atherosclerosis and adventitial mast cells in cocaine abusers: An alternative mechanism of cocaine-associated coronary vasospasm and thrombosis. J. Am. Coll. Cardiol. 1991, 17, 1553-1560. [CrossRef]

29. Omar, A.; Chatterjee, T.K.; Tang, Y.; Hui, D.Y.; Weintraub, N.L. Proinflammatory phenotype of perivascular adipocytes. Arterioscler Thromb. Vasc. Biol. 2014, 34, 1631-1636. [CrossRef]

30. Iacobellis, G.; Pistilli, D.; Gucciardo, M.; Leonetti, F.; Miraldi, F.; Brancaccio, G.; Gallo, P.; di Gioia, C.R.T. Adiponectin expression in human epicardial AT in vivo is lower in patients with coronary artery disease. Cytokine 2005, 29, 251-255. [CrossRef] [PubMed]

31. Eiras, S.; Teijeira-Fernández, E.; Shamagian, L.G.; Fernandez, A.L.; Vazquez-Boquete, A.; Gonzalez-Juanatey, J.R. Extension of coronary artery disease is associated with increased IL-6 and decreased adiponectin gene expression in epicardial AT. Cytokine 2008, 43, 174-180. [CrossRef]

32. Iglesias, M.J.; Eiras, S.; Pineiro, R.; Lopez-Otero, D.; Gallego, R.; Fernandez, Á.L.; Lago, F.; González-Juanatey, J.R. Gender differences in adiponectin and leptin expression in epicardial and subcutaneous Adipose Tissue. findings in patients undergoing cardiac surgery. Rev. Esp. Cardiol. 2006, 59, 1252-1260. [CrossRef]

33. Lee, H.Y.; Despres, J.P.; Koh, K.K. Perivascular AT in the pathogenesis of cardiovascular disease. Atherosclerosis 2013, 230, 177-184. [CrossRef]

34. Withers, S.B.; Bussey, C.E.; Saxton, S.N.; Melrose, H.M.; Watkins, A.E.; Heagerty, A.M. Mechanisms of adiponectin-associated perivascular function in vascular disease. Arterioscler. Thromb. Vasc. Biol. 2014, 34, 1637-1642. [CrossRef]

35. Cybularz, M.; Langbein, H.; Zatschler, B.; Brunssen, C.; Deussen, A.; Matschke, K.; Morawietz, H. Endothelial function and gene expression in perivascular adipose tissue from internal mammary arteries of obese patients with coronary arterydisease. Atheroscler. Suppl. 2017, 30, 149-158. [CrossRef]

36. Payne, G.A.; Kohr, M.C.; Tune, J.D. Epicardial perivascular AT as a therapeutic target in obesity-related coronary artery disease. Br. J. Pharmacol. 2012, 165, 659-669. [CrossRef] 
37. Mazurek, T.; Zhang, L.F.; Zalewski, A.; Mannion, J.D.; Diehl, J.T.; Arafat, H.; Sarov-Blat, L.; O’Brien, S.; Keiper, E.A.; Johnson, A.G.; et al. Human epicardial adipose tissue is a source of inflammatory mediators. Circulation 2003, 108, 2460-2466. [CrossRef]

38. Guo, R.; Han, M.; Song, J.; Liu, J.; Sun, Y. Adiponectin and its receptors are involved in hypertensive vascular injury. Mol. Med. Rep. 2018, 17, 209-215. [CrossRef] [PubMed]

39. Nacci, C.; Leo, V.; De Benedictis, L.; Potenza, M.A.; Sgarra, L.; De Salvia, M.A.; Quon, M.J.; Montagnani, M. Infliximab therapy restores adiponectin expression in perivascularAT and improves endothelial nitric oxide-mediatedvasodilation in mice with type 1 diabetes. Vasc. Pharmacol. 2016, 87, 83-91. [CrossRef] [PubMed]

40. Tao, L.; Gao, E.; Jiao, X.; Yuan, Y.; Li, S.; Christopher, T.A.; Lopez, B.L.; Koch, W.; Chan, L.; Goldstein, B.J.; et al. Adiponectin cardioprotection after myocardial ischemia/reperfusion involves the reduction of oxidative/nitrative stress. Circulation 2007, 115, 1408-14016. [CrossRef] [PubMed]

41. Bauche, I.B.; El Mkadem, S.A.; Rezsohazy, R.; Funahashi, T.; Maeda, N.; Miranda, L.M.; Brichard, S.M. Adiponectin downregulates its own production and the expression of its AdipoR2 receptor in transgenic mice. Biochem. Biophys. Res. Commun. 2006, 345, 1414-1424. [CrossRef] [PubMed]

42. Kadowaki, T. Adiponectin and adiponectin receptors in insulin resistance, diabetes, and the metabolic syndrome. J. Clin. Investig. 2006, 116, 1784-1792. [CrossRef]

43. Hasty, A.H.; Shimano, H.; Osuga, J.; Namatame, I.; Takahashi, A.; Yahagi, N.; Perrey, S.; Iizuka, Y.; Tamura, Y.; Amemiya-Kudo, M.; et al. Severe hypercholesterolemia, hypertriglyceridemia, and atherosclerosis in mice lacking both leptin and the low density lipoprotein receptor. J. Biol. Chem. 2001, 276, 37402-37408. [CrossRef] [PubMed]

44. Gormez, S.; Demirkan, A.; Atalar, F.; Caynak, B.; Erdim, R.; Sozer, V.; Gunay, D.; Akpinar, B.; Ozbek, U.; Buyukdevrim, A.S. Adipose tissue gene expression of adiponectin, tumor necrosis factor alpha and leptin in metabolic syndrome patients with coronary artery disease. Intern. Med. 2011, 50, 805-910. [CrossRef] [PubMed]

45. Polyakova, E.A.; Kolodina, D.A.; Miroshnikova, V.V.; Razgildina, N.D.; Bogdanova, E.O.; Lyapina, E.N.; Belyaeva, O.D.; Pchelina, S.N.; Berkovich, O.A.; Baranova, E.I. Subcutaneous and epicardial adipose tissue leptin gene expression in coronary artery disease patient. Transl. Med. 2019, 6, 25-35. (In Russian) [CrossRef]

46. Bokeriya, L.A.; Aronov, D.M. Russian clinical guidelines. Coronary artery bypass grafting in patients with ischemic heart disease: Rehabilitation and secondary prevention. Cardiosomatics 2016, 7, 5-71. [CrossRef]

47. Drosos, I.; Chalikias, G.; Pavlaki, M.; Kareli, D.; Epitropou, G.; Bougioukas, G.; Mikroulis, D.; Konstantinou, F.; Giatromanolaki, A.; Ritis, K.; et al. Differences between perivascular AT surrounding the heart and the internal mammary artery: Possible role for the leptin-inflammation-fibrosis-hypoxia axis. Clin. Res. Cardiol. 2016, 105, 887-900. [CrossRef]

48. Gotsman, I.; Stabholz, A.; Planer, D.; Pugatsch, T.; Lapidus, L.; Novikov, Y.; Masrawa, S.; Soskolne, A.; Lotan, C. Serum cytokine tumor necrosis factor-alpha and interleukin-6 associated with the severity of coronary artery disease: Indicators of an active inflammatory burden? Isr. Med. Assoc. J. 2008, 10, 494-498.

49. Dandona, P.; Aljada, A.; Chaudhuri, A.; Mohanty, P.; Garg, R. Metabolic syndrome: A comprehensive perspective based on interaction between obesity, diabetes, and inflammation. Circulation 2005, 111, 1448-1454. [CrossRef]

50. Shibasaki, I.; Nishikimi, T.; Mochizuki, Y.; Yamada, Y.; Yoshitatsu, M.; Inoue, Y.; Kuwata, T.; Ogawa, H.; Tsuchiya, G.; Ishimitsu, T.; et al. Greater expression of inflammatory cytokines, adrenomedullin, and natriuretic peptide receptor-C in epicardial AT in coronary artery disease. Regul. Pept. 2010, 165, 210-217. [CrossRef]

51. Yang, R.; Barouch, L.A. Leptin signaling and obesity. Circ. Res. 2007, 101, 545-559. [CrossRef] [PubMed]

52. Fujimaki, S.; Kanda, T.; Fujita, K.; Tamura, J.; Kobayashi, I. The significance of measuring plasma leptin in acute myocardial infarction. J. Int. Med. Res. 2001, 29, 13-108. [CrossRef] [PubMed]

53. Hoene, M.; Weigert, C. The role of interleukin-6 in insulin resistence, body fat distribution and energy balance. Obes. Rev. 2008, 9 , 20-29. [PubMed] 